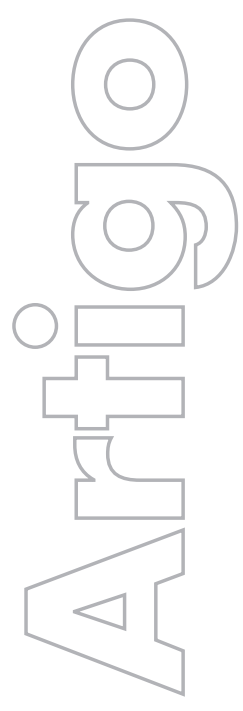

\title{
A ilha de calor urbana e o uso e cobertura do solo em São Paulo-SP
}

\author{
Hugo Rogério Barros \\ USP \\ Magda Adelaide Lombardo \\ Unesp \\ p. $160-177$
}

\section{revista}

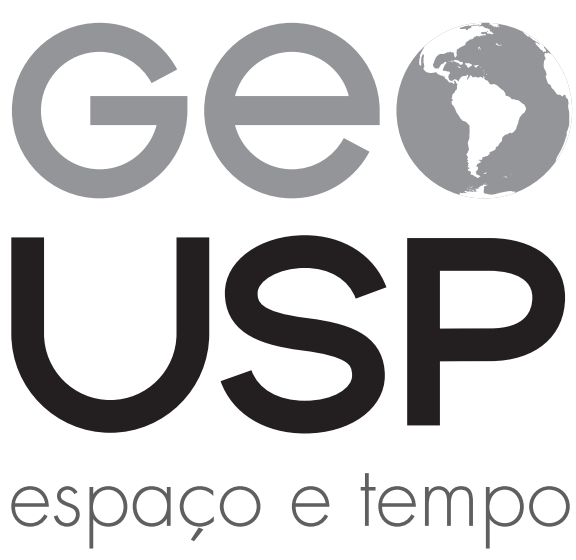

Volume $20 \cdot n^{\circ} 1(2016)$
Como citar:

BARROS, H. R.; LOMBARDO, M. A. A ilha de calor urbana e o uso e cobertura do solo em São Paulo-SP. Geousp - Espaço e Tempo (Online), v. 20, n. 1, p. 160-177, mês. 2016. ISSN 2179-0892.

Disponível em: http://www.revistas.usp.br/geousp/article/ view/97783. DOI: http://dx.doi.org/10.11606/issn.21790892.geousp.2016.97783.

\section{(c) (i) (8)}

Este artigo está licenciado sob a Creative Commons Attribution 4.0 License. 


\title{
A ilha de calor urbana e o uso e cobertura do solo em São Paulo-SP
}

\section{Resumo}

Este trabalho avalia e apresenta a relação espacial entre os diferentes padrões de uso e cobertura do solo e suas respostas térmicas, para compreender a conformação espacial do fenômeno da ilha de calor urbana no território de São Paulo-SP. Para tanto, às análises descritiva e comparativa seguiu-se a integrada descritiva. As variáveis testadas na análise espacial foram o índice de área foliar, a temperatura da superfície e o uso do solo, além da classificação térmica da ilha de calor urbana. Verificou-se que os ambientes sem vegetação, principalmente nos espaços ocupados por atividades industriais, de comércio ou serviços, apresentaram forte intensidade do fenômeno, com diferenças de temperatura da superfície superiores a $8^{\circ} \mathrm{C}$. Assim, constatamos a importância do arboreto urbano e de áreas verdes para amenizar as temperaturas da superfície dos espaços urbanos do município de São Paulo.

Palavras-chave: llha de calor urbana. Uso do solo. Índice de área foliar. São Paulo. Temperatura da superfície.

\section{The urban heat island and land use and land cover in São Paulo-SP}

\begin{abstract}
The current work has focused on evaluating and presenting the spatial relationship among different land use and land cover patterns and their thermal responses, in order to understand the spatial constitution of the urban heat island (UHI) in the municipality of São Paulo-SP. For that, descriptive and comparative analyses were used, followed by an integrated descriptive analysis. The variables tested in the spatial analysis were the Leaf Area Index, surface temperature, land use and the thermal classification of the UHI. Urban environments lacking vegetation, especially those occupied by industrial and commercial activities, presented a stronger intensity of the $\mathrm{UHI}$, with temperature differences of up to $8{ }^{\circ} \mathrm{C}$. The results highlighted the importance of green urban spaces for the decrease of temperature in the urban environments of the São Paulo municipality.
\end{abstract}

Keywords: Urban heat island. Land use. Leaf area index. São Paulo. Surface temperature. 


\section{Introdução}

As cidades e suas configurações heterogêneas apresentam distintos padrões de edificações, habitações e espaços públicos. Sua formação e expansão, com o contínuo processo de substituição das superfícies naturais por materiais artificiais e lançamento de gases e material particulado na atmosfera, concorrem para a degradação ambiental e a mudança dos padrões climáticos locais (Ferreira; Oliveira; Soares, 2010). Elas criam seus próprios climas devido ao impacto do desenvolvimento urbano no balanço de calor à superfície (Oke et al., 1999), e esse processo condiciona a formação do fenômeno da ilha de calor urbana.

A ilha de calor urbana (ICU), evento reconhecido a mais de um século, é o mais claro e o mais bem documentado exemplo de mudança climática provocado pela ação antrópica (Oke, 1978, p. 254). Sua natureza complexa se relaciona com outros importantes fatores climáticos como poluição atmosférica, fortes precipitações com risco de inundações e alteração nas amplitudes térmicas, além da dinâmica de uso e cobertura do solo e outros conjuntos de variáveis como habitação e saúde pública.

primeiro estudo sobre a ilha de calor urbana para o município de São Paulo e sua região metropolitana foi realizado por Lombardo (1985), que verificou sua variação diurna, sazonal e espacial por meio da combinação de medições de temperatura e umidade relativa de 45 pontos de coleta, ao lado do uso de imagens termais com cálculo da temperatura da superfície na resolução espacial de $1 \mathrm{~km} \times 1 \mathrm{~km}$.

Ribeiro (1996) estudou a variação diurna e sazonal, em uma abordagem intraurbana no município de São Paulo, ao avaliar as diferenças das respostas térmicas em diferentes padrões de uso do solo urbano, através da combinação de 3 estações fixas e a temperatura da superfície gerada com uma imagem termal do satélite Landsat 7. Tarifa e Armani (2001) também usaram a temperatura da superfície das imagens termais do mesmo imageador para definir as unidades climáticas urbanas em conjunto com variáveis como morfologia e uso do solo.

Estudos meteorológicos como os de Ferreira, Oliveira e Soares (2013) e Ferreira et al. (2012), apresentam um importante avanço no desenvolvimento metodológico na abordagem da problemática. Estes foram além das tradicionais medições de temperatura e umidade com estações fixas em diferentes usos do solo. Acrescentaram-se variáveis como fluxo de calor sensível e latente, saldo de radiação e o armazenamento do fluxo de energia para um ponto localizado no Instituto de Astronomia, Geofísica e Ciências Atmosféricas da Universidade de São Paulo para entender a interferência dos processos físicos na variação diurna e sazonal da ilha de calor urbana.

Catuzzo (2013) avaliou a eficiência do telhado verde para a minimização das alterações no microclima urbano no centro da cidade de São Paulo, através da análise comparativa com medições de temperatura e umidade relativa do ar para um telhado verde intensivo e outro de concreto, localizados na mesma quadra urbana. $\bigcirc$ autor diagnosticou que o telhado verde intensivo é uma possível fonte mitigatória para a ilha de calor urbana em São Paulo.

Diante do estado da arte referente aos estudos da ilha de calor urbana em São Paulo, diagnosticamos a falta de uma apresentação cartográfica atual, que permita representar os elementos espaciais de uso e cobertura do solo com a intensidade e distribuição espacial do fenômeno. 
Com 11.253 .503 habitantes e uma área de $1.521 \mathrm{~km}^{2}$, tem densidade demográfica de $7.898,2 \mathrm{hab} / \mathrm{km}^{2}$ e uma frota de 6.390.092 veículos (IBGE, 2010). O município de São Paulo vive problemas cotidianos ligados a eventos de alta concentração de poluentes atmosféricos, inundações, ondas de frio e ilhas de calor, aliados a um grande contingente populacional com alta vulnerabilidade socioeconômica e ambiental. Tal quadro é refletido na relação entre temperatura do ar e mortalidade no município, onde o acréscimo de $1{ }^{\circ} \mathrm{C}$ na temperatura média corresponde a um aumento de 3,46\% da mortalidade geral e 3,26\% das cardiovasculares e respiratórias (McMichael et al., 2008).

O presente trabalho visa avaliar e apresentar cartograficamente a relação espacial entre os distintos padrões de uso e cobertura do solo e suas respostas térmicas, a fim de compreender a conformação espacial do fenômeno da ilha de calor urbana no território do município de São Paulo.

\section{Material e métodos}

A metrópole paulistana está a uma latitude aproximada de $23^{\circ} 21^{\prime}$ e à longitude de $46^{\circ} 44^{\prime}$, junto ao Trópico de Capricórnio (Figura 1). Fica num contexto de terras altas (predominantemente entre $720 \mathrm{~m}$ e $850 \mathrm{~m}$ ) chamado de Planalto Atlântico, o que implica uma realidade climática de transição entre os climas tropicais úmidos de altitude, com período seco definido, e aqueles subtropicais, permanentemente úmidos, do Brasil meridional (Tarifa; Armani, 2001).

Avaliando as normais climatológicas do período 1961-1990 da Estação meteorológica do Mirante de Santana (lat. 2330’, long. 46³7, alt. 792), Tarifa e Armani (2001) identificaram duas estações bem definidas no município em questão, uma quente e chuvosa, de outubro a março (grosso modo, primavera-verão), e outra fria e relativamente seca, de abril a setembro (outono-inverno). O comportamento térmico mostra variação sazonal muito semelhante, com período de maio a outubro registrando os menores valores médios de temperatura, com uma variação entre $15,8^{\circ} \mathrm{C}$ (julho, mês mais frio) a $19,0^{\circ} \mathrm{C}$ (outubro). Na estação quente, os valores oscilam entre $22,4^{\circ} \mathrm{C}$ (fevereiro mês mais quente) e $20,3^{\circ} \mathrm{C}$ (novembro), a média anual dos valores foi de $25,9^{\circ} \mathrm{C}$.

A geomorfologia da mesma reflete a existência de um relevo colinoso com planícies aluviais e terraços dos rios Tietê e Pinheiros e afluentes, onde se encontra assentado seu núcleo urbano mais consolidado, circundado por formas de relevo mais salientes sustentados por corpos graníticos (Serra da Cantareira) e lentes de metassedimentos mais resistentes. A vegetação predominante é floresta ombrófila, densa "mata", classificada em alto montana (mata nebular), sobre turfeira, campos naturais (campos altos montanos), seguida de reflorestamento "bosque de pinus" e formação de várzea-campos (brejo). O município fica dentro da Bacia Hidrográfica do Alto Tietê e está dividida em seis sub-bacias, que drenam os principais rios na Região Metropolitana de São Paulo, entre elas abrange a sub-bacia Billings-Tamanduateí, sub-bacia Jusante Pinheiros-Pirapora e sub-bacia Penha-Pinheiros (PMSP, 2000). 


\section{Figural - Mapa de localização do município de São Paulo}
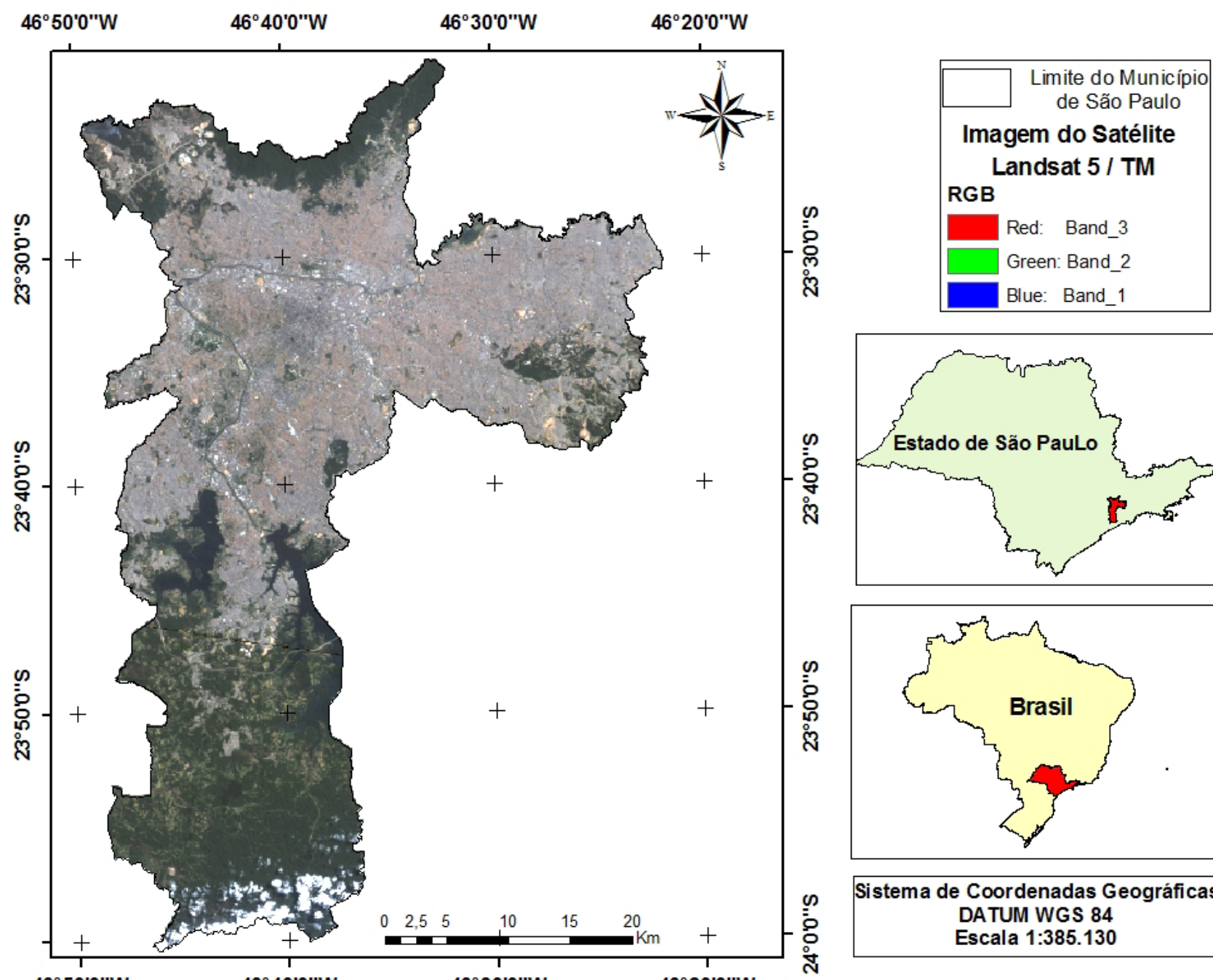

$46^{\circ} 50^{\prime} 0$ "W

$46^{\circ} 40^{\prime} 0^{\prime \prime} \mathrm{W}$

$46^{\circ} 30^{\prime} 0^{\prime \prime} \mathrm{W}$

$46^{\circ} 20^{\prime} 0^{\prime \prime} \mathrm{W}$
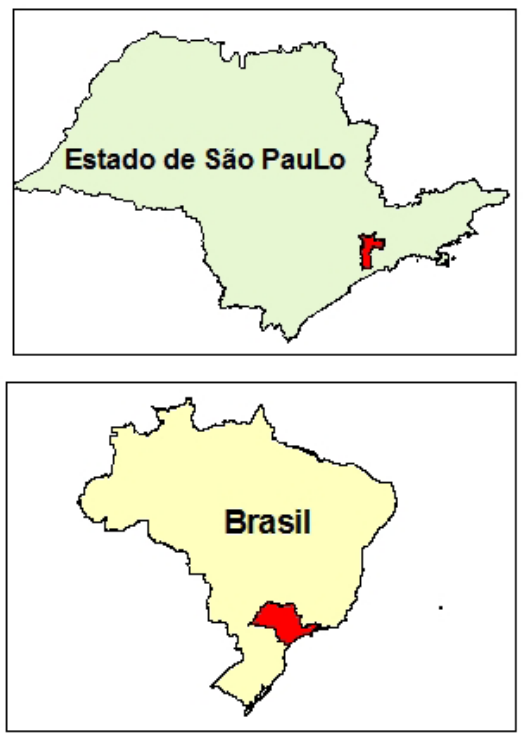

Sistema de Coordenadas Geográficas DATUM WGS 84

Escala 1:385.130

As metodologias utilizadas para análise dos resultados foram a análise descritiva, seguida da comparativa e pôr fim a análise integrada descritiva. As variáveis adotadas foram o índice de área foliar, a temperatura da superfície, os padrões de uso do solo e, por fim, a classificação termal da ilha de calor urbana.

A temperatura da superfície estimada através da banda termal das imagens de satélite, atualmente, é a melhor opção para avaliação espacial das temperaturas em grandes áreas. Os pioneiros no emprego dessas temperaturas na avaliação do fenômeno da ilha de calor urbana foram Matson (1978), que detectou mais de 50 ilhas de calor urbanas no oeste e no nordeste dos EUA, e, na região tropical do globo terrestre, Lombardo (1985), que detectou e avaliou a ilha de calor na Região Metropolitana de São Paulo. Desde então, a aplicação de tais técnicas na avaliação do fenômeno se multiplicaram pelo globo, pois é extremamente difícil estimar a temperatura do ar dos ambientes urbanos, visto que as estações meteorológicas ficam frequentemente em parques e aeroportos (Laaidi et al., 2012), de modo que não atendem à heterogeneidade da malha urbana. 
A ilha de calor urbana habitualmente é retratada como aumento da temperatura do ar dos ambientes urbanos em relação ao seus arredores, porém a mediação da temperatura do ar em escala espacial por meio de sensores remotos, até o momento da vigente pesquisa, não é uma metodologia disponível do ponto de vista tecnológico e estrutural. Com isso, a temperatura da superfície medida via satélite é uma alternativa viável e eficiente para estudos espaciais dos fenômenos relativos à temperatura do ar na baixa atmosfera, visto que esta tem relação estreita com a radiação de onda longa emitida pela superfície.

A base da metodologia aqui empregada é a transformação dos dados matriciais da temperatura da superfície medida via satélite em camadas vetoriais segundo uma simples classificação dos valores, que, num sistema de informações geográficas, se possa sobrepor a outras camadas de informações como índice de vegetação, que representa a cobertura do solo e os padrões de uso do solo.

Nos estudos de clima urbano, é bastante comum adotar a divisão do comportamento espacial do gradiente de temperatura em ilhas de calor e frescor urbanas. A metodologia vigente consiste em empregar essa base clássica de classificação e acrescentar mais uma subdivisão, que é a ilha de calor moderada, representando as áreas de transição entre os ambientes mais quentes e os mais frios da malha urbana e atribuir-lhes uma cartografia própria, para avaliar os fatores intraurbanos que determinam suas conformações espaciais pela sobreposição das camadas de informações.

Do ponto de vista teórico, a metodologia se assemelha ao trabalho desenvolvido por Tarifa e Armani (2001), em que variáveis como temperatura da superfície, poluição atmosférica e o uso do solo foram inter-relacionadas para apresentar um ordenamento territorial do município de São Paulo em unidades climáticas urbanas. A cartografia do estudo apresentou subdivisões que aglomeraram o conjunto das informações, mas a base principal da legenda foram as características da malha urbana estudada. Assim, ainda é um desafio metodológico para o município de São Paulo apresentar uma cartografia temática para o fenômeno da ilha de calor urbana, suas subdivisões e variáveis que a condicionam.

Para simplificar as análises e a apresentação dos resultados, a classificação térmica aqui adotada tem apenas três subdivisões, pois o território do município de São Paulo tem $1.521 \mathrm{~km}^{2}$ e ampla variedade de arranjos espaciais, de modo que um grande número de variáveis pode dificultar a identificação das relações espaciais. A classificação termal adotada aqui tem uma estrutura simples e foi desenvolvida pelos próprios autores para o estudo em questão, visto que o objetivo principal é a apresentação cartográfica da ilha de calor urbana, e não atende a objetivos de outras naturezas como, por exemplo, o estudo do conforto térmico.

O cálculo para determinação da ilha de calor urbana consistiu no resultante das diferenças das temperaturas da superfície do centros urbanos em relação ao seus arredores rurais, de modo a determinar o valor do delta de temperatura $(\Delta T)$. Para o município de São Paulo, o distrito não urbano de Parelheiros, no extremo sul do território, foi tomado como parâmetro para o cálculo do delta de temperatura. As divisões contemplaram três simples unidades, para simplificar e facilitar as análises; seus valores foram estabelecidos segundo o mesmo critério (Quadro 1). 


\section{Quadro 1 - Padrões da classificação termal}

\begin{tabular}{l|l}
\hline ilha de calor forte & $\Delta \mathrm{T}>8^{\circ} \mathrm{C}$ \\
\hline ilha de calor moderado & $5^{\circ} \mathrm{C}<\Delta \mathrm{T}<7^{\circ} \mathrm{C}$ \\
\hline ilha de frescor & $\Delta \mathrm{T}<4^{\circ} \mathrm{C}$ \\
\hline
\end{tabular}

Para a realização do presente trabalho foram utilizadas duas imagens do mapeador temático Landsat 5 com data de passagem em 28/09/2011 da órbita 219, do ponto 66 e 67, com horário médio de passagem às $10 \mathrm{~h}$ da manhã, adquiridas através de download gratuito do catálogo de imagens do Instituto Nacional de Pesquisas Espaciais (Inpe). Em seguida as mesmas passaram por uma etapa de tratamento que incluiu composição das bandas, realce em falsa cor, correção geométrica, mosaico e recorte da área de estudo, tais procedimentos foram realizados no software Erdas 9.1 .

A partir do processamento das imagens no mesmo software foram computadas duas variáveis, a primeira foi o índice de área foliar (IAF) e a segunda foi a temperatura da superfície. Os dados cartográficos com limites territoriais e hidrografia foram extraídos da base do Atlas Ambiental do Município de São Paulo (PMSP, 2002), enquanto os padrões de uso do solo foram adaptados do mapa da prefeitura de São Paulo para o ano de 2010.

Primeiramente, foram computadas e avaliadas as temperaturas da superfície, que depois foram vetorizadas e classificadas de acordo com os intervalos de valores estabelecidos nesta metodologia e sobrepostas ao IAF, para avaliar a influência da distribuição da vegetação na conformação espacial da ilha de calor. Por fim, a classificação térmica foi sobreposta aos padrões de uso do solo estabelecidos pela Prefeitura do Município de São Paulo.

Para as variáveis primárias medidas aqui, IAF e temperatura da superfície, foram organizados mapas com a sobreposição dos limites mínimos administrativos do município de São Paulo - os distritos - para facilitar a análise espacial e localização das relações estabelecidas. Por fim, organizaram-se tabelas de correlações para sintetizar o conjunto dessas relações. $\bigcirc$ layout de todos os mapas foi editado no aplicativo Arc' gis 9.3.

\section{Etapas técnicas}

No tocante aos dados gerados por sensoriamento remoto, a primeira variável medida foi o índice de vegetação, que, no entanto, demanda adequação para anular os efeitos do solo exposto e úmido na resposta espectral das bandas termais 3 e 4 do imageador temático Landsat 5. Diante disso, selecionou-se e computou o IAF, definido pela razão entre a área foliar de toda a vegetação por unidade de área ocupada por essa vegetação.

Para chegar ao índice referido, foi preciso calcular o índice de vegetação ajustado para os efeitos do solo (Soil Adjusted Vegetation Index - Savi), que busca amenizar os efeitos do background do solo. Para isso, tem-se usado a expressão (Huete, 1988): 
1. Equação para obtenção do Savi:

$$
\mathrm{SAVI}=\frac{(1+\mathrm{L})\left(\rho_{\mathrm{IV}}-\rho_{\mathrm{V}}\right)}{\left(\mathrm{L}+\rho_{\mathrm{IV}}+\rho_{\mathrm{V}}\right)}
$$

Onde o fator $L$ é uma função do tipo de solo. Em estudo recente, utilizamos $L=0,1$, embora o seu valor mais frequente seja $\mathrm{L}=0,5$. $\bigcirc \mathrm{IAF}$ é um indicador da biomassa de cada pixel da imagem e o mesmo foi computado pela seguinte equação empírica obtida por Allen, Trezza e Tasumi (2002):

2. Equação para obtenção do IAF:

$$
I A F=-\frac{\ln \left(\frac{0,69-S A V I}{0,59}\right)}{0,91}
$$

A segunda variável computada por sensores remotos foi a temperatura da superfície, para o computo desta foi necessário o cálculo da emissividade atmosférica.

\section{Emissividade}

Para obter a temperatura da superfície, usou-se a equação de Planck invertida, válida para um corpo negro. Como cada pixel não emite radiação eletromagnética como um corpo negro, há a necessidade de introduzir a emissividade de cada pixel no domínio espectral da banda termal $\varepsilon_{\mathrm{NB}}$, qual seja: 10,4-12,5 $\mu \mathrm{m}$. Por sua vez, quando do cômputo da radiação de onda longa emitida por cada pixel, há de ser considerada a emissividade no domínio da banda larga $\varepsilon_{0}(5-100 \mu \mathrm{m})$. Segundo Allen, Trezza e Tasumi (2002), as emissividade $\varepsilon_{\mathrm{NB}}$ e $\varepsilon_{0}$ podem ser obtidas, para NDVI $>0$ e IAF $<3$, segundo:

3 - Equação para obtenção da emissividade de cada pixel no domínio espectral da banda termal:

$$
\varepsilon_{\mathrm{NB}}=0,97+0,0033 \cdot \mathrm{IAF}
$$

Para pixels com IAF $\geqslant 3, \varepsilon_{\mathrm{NB}}$ e $\varepsilon_{0}=0,98$ e para corpos de água $(\mathrm{NDVI}<0) \varepsilon_{\mathrm{NB}}=0,99$, conforme recomendações de Allen, Trezza e Tasumi (2002). 


\section{Temperatura da superfície}

Para a obtenção da temperatura da superfície $\left(\mathrm{T}_{\mathrm{s}}\right)$ são utilizadas a radiância espectral da banda termal $L_{\lambda, 6}$ e a emissividade $\varepsilon_{\mathrm{NB}}$ obtida na etapa anterior. Assim, obtém-se a temperatura da superfície $(K)$ pela seguinte expressão:

4 - Equação para obtenção da temperatura da superfície:

$$
\mathrm{T}_{\mathrm{S}}=\frac{\mathrm{K}_{2}}{\ln \left(\frac{\varepsilon_{\mathrm{NB}} \mathrm{K}_{1}}{\mathrm{~L}_{\lambda, 6}}+1\right)}
$$

onde $K_{1}=607,76 \mathrm{wm}^{-2} \mathrm{sr}-1 \mu \mathrm{m}^{-1}$ e $\mathrm{K}_{2}=1260,56 \mathrm{~K}$ são constantes de calibração da banda termal do Landsat 5-TM (Allen, Trezza e Tasumi , 2002; Silva; Lopes; Azevedo, 2005).

Os resultados estão organizados na seguinte ordem, primeiro se discute e apresenta os dados da temperatura da superfície com sobreposição da camada de informações dos distritos administrativos. Em seguida os dados da vegetação são apresentados com sobreposição dos distritos administrativos e por seguinte a classificação termal (ilha de calor e frescor) é apresentada sobreposta aos valores de biomassa vegetal. Por fim a classificação térmica é sobreposta aos dados de uso do solo. Tabelas de correlação acompanham os resultados finais, para melhor esclarecer as relações entre a vegetação, o uso do solo e o comportamento térmico da superfície do município de São Paulo.

\section{Resultados e discussão \\ Temperatura da superfície}

$\bigcirc$ gradiente de temperatura da superfície medido através da banda termal do satélite Landsat 5, sensor TM, apresentou os menores valores espaciais em torno de $17^{\circ} \mathrm{C}$, estes estão concentrados nos limites do extremo norte (Serra da Cantareira), extremo leste (Parque do Carmo) e ao extremo Sul (Área de Preservação Permanente Capivari-Monos e Bororé-Colônia). Os distritos mais representativos são Parque do Carmo (31), José Bonifácio (50), Marsilac (51), Parelheiros (52) e Ipiranga (89) (Figura 2).

Os valores intermediários, ou seja, aqueles que estão entre as máximas e as mínimas apresentaram variação entre 20 e $25^{\circ} \mathrm{C}$, estão predominantemente concentrados no centro oeste e em algumas porções do sul do território municipal. Os distritos mais representativos são Butantã (9), Consolação (16), Jardim Paulista (21), Moema (26), Morumbi (28) e Vila Andrade (44) (Figura 2).

Os maiores valores de temperada da superfície medidos foram superiores a $27{ }^{\circ} \mathrm{C}$ e formaram um anel em torno da área centro-oeste do território do municipal, com uma grande ramificação na área sudeste. Os distritos mais representativos são Aricanduva (3), Brás (7), Cambuci (15), São Mateus (85), Sapopemba (86) e São Lucas (87) (Figura 2). 
Figura 2 - Mapa da temperatura da superfície do município de São Paulo

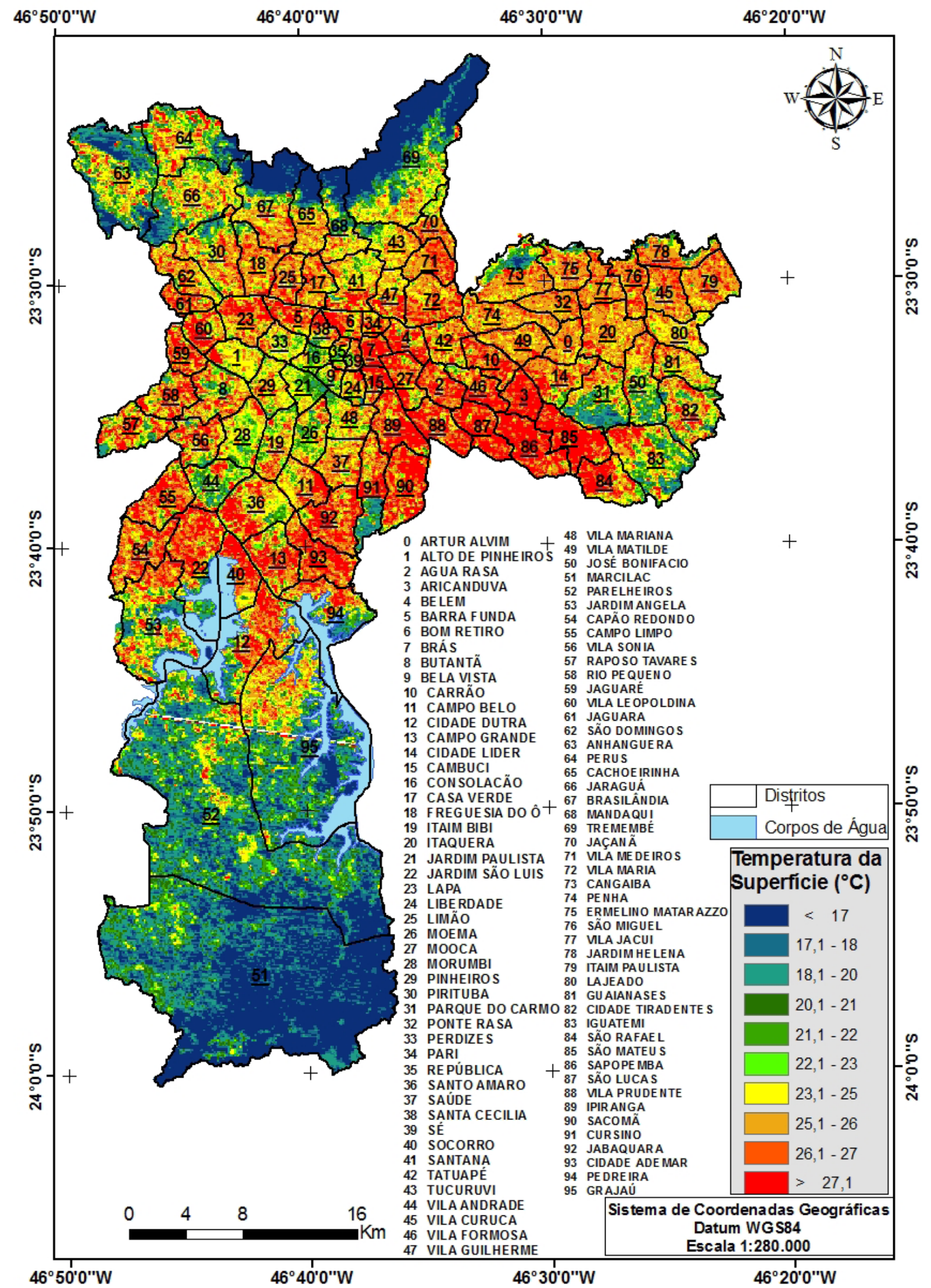




\section{Índice de área foliar}

A distribuição espacial do índice de vegetação indica três tipos de variação na quantidade de biomassa presente no território municipal. A primeira foi denominada cinturão verde, a segunda corresponde às áreas urbanas vegetadas e a terceira, às áreas urbanas sem vegetação.

município tem forte escassez de ambientes com presença espacialmente representativa de vegetação em sua área urbana, de modo que a mancha urbana é predominantemente dominada por valores nulos ou muito próximos a 0 de biomassa vegetal, o que os distingue dos limites extraurbanos, onde é alta a concentração de vegetação (Figura 3).

Cinturão Verde: os valores variam entre 0,39 e 0,83 e apresenta características de ambientes periféricos fora dos limites da área urbana; tem extensas áreas verdes, com vegetação que varia entre pomares, Mata Atlântica terciária e campos abertos interceptados por vegetação arbórea e arbustiva.

Ao extremo sul o cinturão verde abrange os distritos de Grajaú (95), Parelheiros (52) e Marsilac (51), outro eixo no extremo leste abrange Iguatemi (83), Cidade Tiradentes (82), Guaianazes (81), José Bonifácio (50) e Parque do Carmo (31). O último trecho corresponde ao extremo norte respectivo a Anhaguera (63), Perus (64), Jaraguá (66), Brasilândia (67), Cachoeirinha (65), Mandaqui (68) e Tremembé (69), com sua maior área pertencente à Serra da Cantareira (Figura 3).

Áreas Urbanas Vegetadas: Alguns poucos espaços dentro da extensa mancha urbana de São Paulo apresentam um intermediário e elevado padrão de quantidade de biomassa. Os valores predominam entre 0,01 e 0,24 com alguns trechos com variação ente 0,39 e 0,51 de biomassa vegetal, a localização predomina na zona oeste e trechos da zona sul. A configuração predomina sobre os seguintes distritos: Alto de Pinheiros (1), Perdizes (33), Consolação (16), Pinheiros (29), Butantã (8), Jardim Paulista (21), Morumbi (28), Itaim Bibi (19), Moema (26), Santo Amaro (36), Vila Andrade (44) e Raposo Tavares (57) (Figura 3).

Áreas com Ausência de Vegetação: a área urbana do município de São Paulo mostrou-se muito pobre quanto à presença de grandes valores da quantidade de biomassa vegetal por pixel medido, houve predomínio do valor 0 com algumas interseções espaciais que variam entre 0,01 e 0,24. Seu foco é a região central da cidade, que abrange os distritos da Sé (39), de Santa Cecília (38), da Liberdade (24), da Mooca (27) e do Bom Retiro (6). No eixo nordeste, estão a Vila Medeiros (27), a Vila Maria (72) e a Vila Guilherme (47); a sudeste, o Sacomã (90) e o Ipiranga (89); e, a leste, a Água Rasa (2), a Vila Prudente (88), São Lucas (87) e Sapopemba (86) (Figura 3). 


\section{Figura 3 - Mapa do índice de área foliar do município de São Paulo}

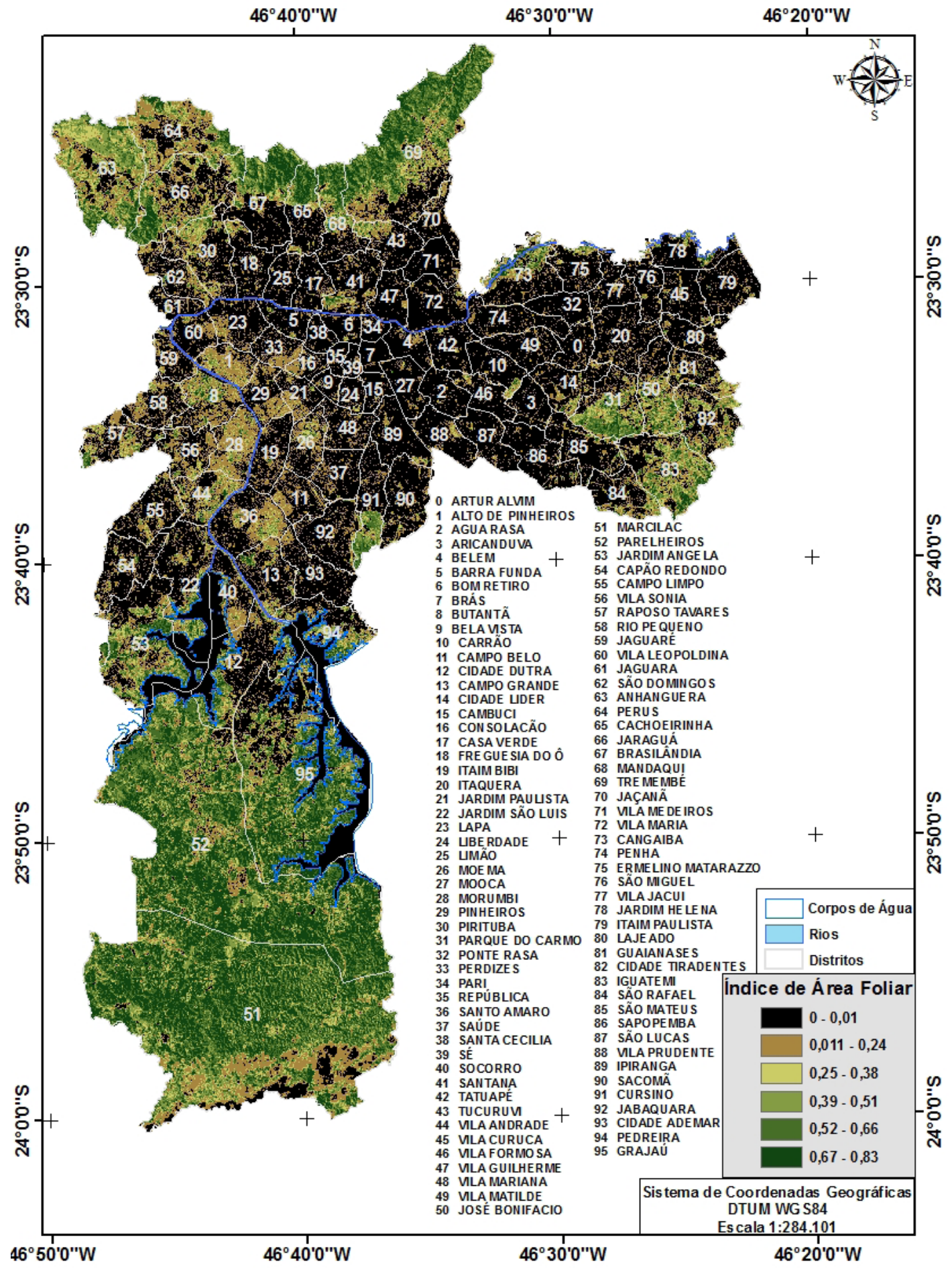

\section{Classificação térmica}

A análise da temperatura da superfície do município de São Paulo, medida através de sensores remotos, nos permitiu estabelecer três diferentes padrões de classificação, são elas: as ilha de calor forte, ilha de calor moderado e ilha de frescor. Estas representam a variação da intensidade do gradiente de variação da temperatura da superfície, entre os ambientes rurais e as áreas urbanas do município de São Paulo. Cada eixo das ilhas de calor e frescor urbanas está devidamente numerado nos mapas seguintes. 
A ilha de calor forte apresenta o coeficiente da diferença de temperaturas da superfície superior a $8^{\circ} \mathrm{C}$, em relação aos ambientes rurais. Essas bolhas de calor apresentaram valores, em geral, maiores do que $27^{\circ} \mathrm{C}$. Há formação de um extenso arquipélago de calor, composto por um conjunto de seis ilhas urbanas de calor forte, distribuídas em eixos que são compostos por conjuntos de distritos (Figura 4).

Eixo 1: localizado a sul do rio Tietê, abrange o norte do distrito da Lapa além de Vila Leopoldina, Jaguaré, Barra Funda e Pari.

Eixo 2: localizado no centro urbano do município corresponde aos distritos de Santa Cecilia, Sé, Brás, Cambuci, Mooca e Belém.

Eixo 3: localizado no sudeste é composto por Ipiranga, Sacomã e Cursino.

Eixo 4: localizado na Zona Leste, é formado por Vila Prudente, São Lucas, Sapopemba, Arincanduva, São Mateus e São Rafael.

Eixo 5: localizado no extremo sul da área urbana, a norte dos grandes corpos de água (reservatórios), abrange, nas proximidades do rio Pinheiros, Santo Amaro e, em seguida, Jardim São Luís, Capão Redondo, Campo Limpo, Socorro, Campo Grande, Cidade Ademar e Jabaquara.

Eixo 6: localizado na Zona Norte, compreende o leste da Vila Medeiros, o sul da Vila Maria e a Vila Guilherme.

As ilhas de calor moderado correspondem aos valores intermediários, cuja temperatura da superfície varia entre 5 e $7^{\circ} \mathrm{C}$ em relação aos ambientes rurais: na cidade, as temperaturas da superfície variaram entre 23 e $25^{\circ} \mathrm{C}$, com representatividade espacial em três diferentes eixos (Figura 4).

Eixo 7: Localizado na Zona Norte, abrange os distritos de Tucuruvi, Perus, Jaraguá e Anhaguera.

Eixo 8: Localizado na Zona Leste do município, no trecho mais a nordeste, próximo ao rio Tietê, é composto pelos distritos da Penha, Ponte Rasa, Vila Matilde, Lajedo e Itaquera.

Eixo 9: Localizado no extremo sul e extremo oeste da área urbana municipal, próximo aos reservatórios de água, é composto pelos distritos de Jardim Ângela e Cidade Dutra, no sul, e Raposo Tavares e Rio Pequeno, no oeste.

A ilha de frescor urbana corresponde a uma extensa área que forma um oásis térmico em meio às quentes e condensadas áreas urbanas e fica no centro-oeste e no sul do território municipal. As temperaturas da superfície para esta variaram entre 0 e $4^{\circ} \mathrm{C}$, em relação aos ambientes rurais. Tais números revelam uma variação mínima se comparada ao total do gradiente medido. Os valores de temperatura da superfície variaram, no geral, em torno de 20 a $23^{\circ} \mathrm{C}$ (Figura 4).

Eixo 10: Localizado no centro oeste e sul do município, os principais distritos que formam esse núcleo são: Jardim Paulista, Pinheiros, Consolação, Perdizes, Alto de Pinheiros, Butantã, Morumbi, Vila Mariana e Vila Andrade.

\section{A classificação térmica e a cobertura do solo}

Para análise da cobertura do solo, foi usado o IAF, que permitiu a avaliação espacial da distribuição da biomassa vegetal pelo território do município de São Paulo. A sobreposição da classificação térmica sobre o IAF, possibilitou as seguintes avaliações: 
As ilhas de frescor urbanas apresentaram relação espacial com as áreas urbanas vegetadas, citadas anteriormente. Tais espaços apresentaram variação numérica do valor de biomassa vegetal entre 0,24 e 0,66.

A análise comparativa detalhada entre os valores de biomassa vegetal para as ilhas de calor moderado e as fortes, revelou que a maior concentração da vegetação diminui a intensidade do fenômeno para o município estudado. Os padrões espaciais da cobertura vegetal, demonstraram ser uma das variáveis responsáveis pela conformação espacial das ilhas de frescor e calor urbanas.

\section{Figura 4 - Mapa do índice de área foliar e classificação termal de} São Paulo

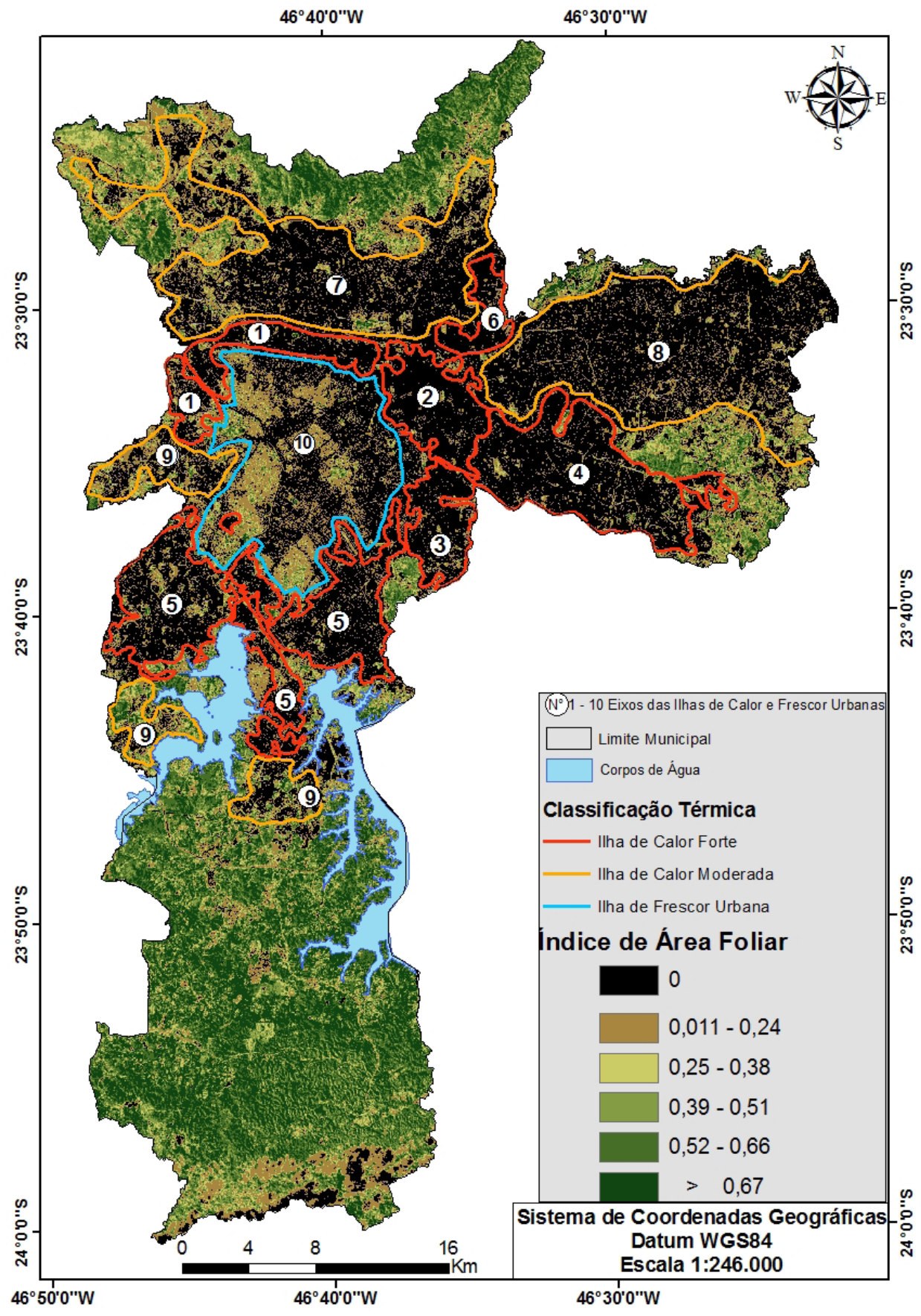




\section{A classificação térmica e o uso do solo}

A relação espacial entre a classificação termal das temperaturas da superfície e os padrões de uso do solo é muito complexa de ser estabelecida apenas pela análise gráfica do layout de mapa. Estimamos que exista relação entre ambas as variáveis, mas ela não é linear, visto que, num padrão de classificação definido para uma escala de 1:246.000, são bastante heterogêneos os tipos de cobertura de superfície (Figura 5).

Figura 5 - Mapa do uso do solo e classificação termal do município de São Paulo

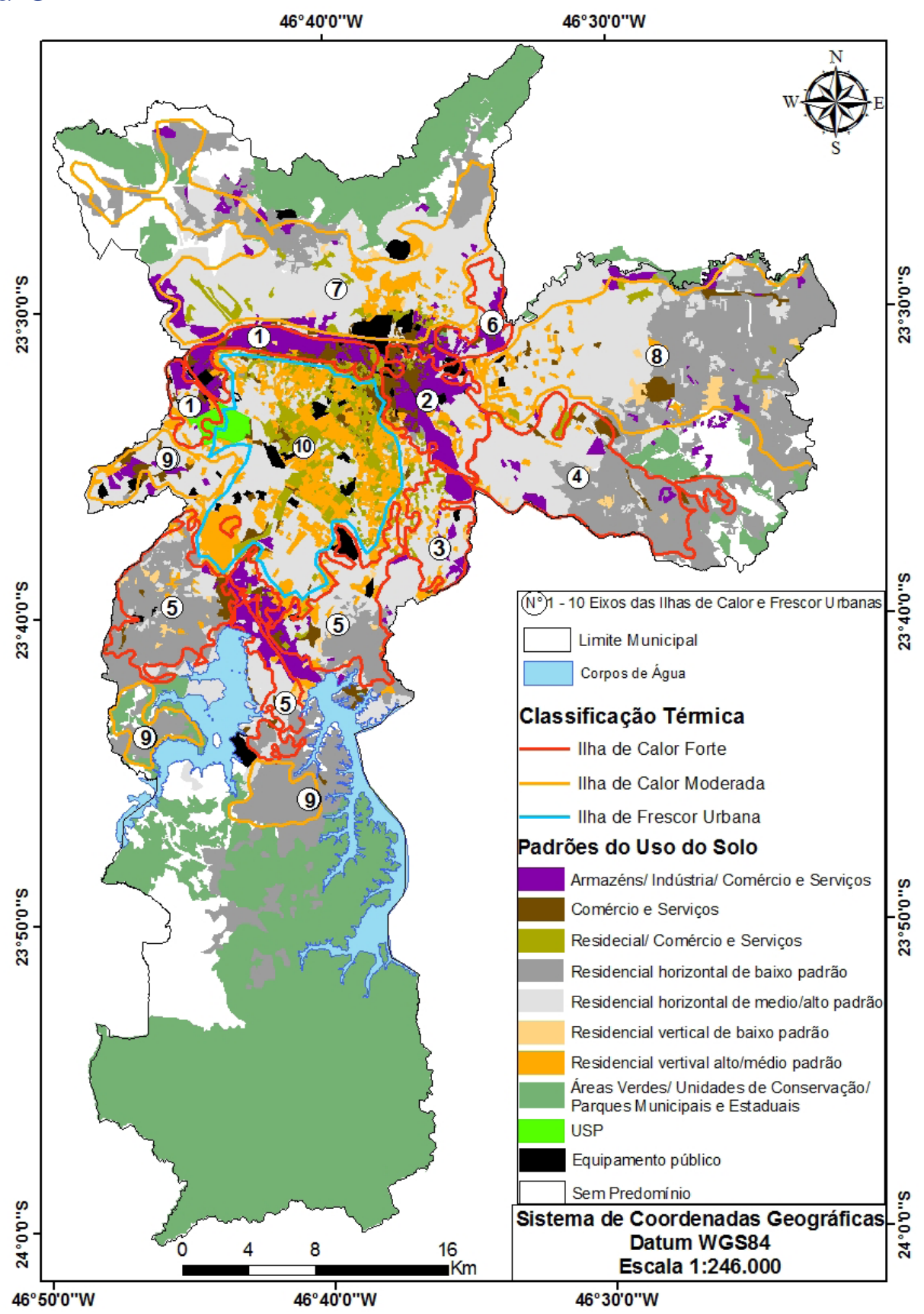

Para melhor compreender a correlação entre a classificação térmica, a cobertura do solo e o tipo de uso realizado sobre o mesmo, os dados medidos e coletados foram tabulados segundo a classificação das ilhas de calor e frescor urbanas 
Os valores do IAF para as ilhas de calor forte variaram entre 0,0 e 0,01, ou seja, com quase ou total ausência de biomassa vegetal, algumas poucas exceções espaciais apresentaram valores de 0,38. Os usos predominantes foram os de armazéns/indústria, comércio e serviços, além do habitacional de alto, médio e baixo padrão sem vegetação (Tabela 1).

\section{Tabela 1 - Tabulação da correlação entre a ICU forte, o IAF e o uso do solo}

ilha de calor forte

\begin{tabular}{|c|c|c|c|}
\hline eixos & uso do solo & IAF & distritos \\
\hline $1,2,3$ e 5 & $\begin{array}{l}\text { armazéns/Indústria, } \\
\text { comércio e serviços }\end{array}$ & $0,0-0,01$ & $\begin{array}{l}\text { Jaguará, Vila Leopoldina, Lapa, Barra Funda, } \\
\text { Brás, Belém, Cambuci, Mooca, Ipiranga, Santo } \\
\text { Amaro, Campo Grande e Socorro }\end{array}$ \\
\hline 1 e 2 & comércio e serviços & $0,0-0,01$ & $\begin{array}{l}\text { toda a Sé e alguns trechos do Brás, Vila Guilher- } \\
\text { me e Barra Funda }\end{array}$ \\
\hline 4 e 5 & $\begin{array}{l}\text { residencial horizon- } \\
\text { tal de baixo padrão }\end{array}$ & $0,0-0,01$ & $\begin{array}{l}\text { Capão Redondo, Jardim São Luís, São Rafael, } \\
\text { São Mateus, Sapopempa }\end{array}$ \\
\hline 3,4 e 5 & $\begin{array}{l}\text { residencial horizon- } \\
\text { tal de médio e alto } \\
\text { padrão }\end{array}$ & $0,0-0,38$ & $\begin{array}{l}\text { Socorro, Jabaquara, Cursino, Sacomã, Água } \\
\text { Rasa, Vila Prudente, São Lucas e Vila Medeiros }\end{array}$ \\
\hline
\end{tabular}

Em meio às condensadas áreas urbanas, a ICU moderada justifica-se por apresentar valores de biomassa vegetal mais elevados em relação à forte, sua variação predominou entre 0,38 e 0,51. O tipo de uso do solo predominante para tal padrão de classificação foram os residenciais horizontais de alto, médio e baixo padrão (Tabela 2).

\section{Tabela 2 - Tabulação da correlação entre a ilha de calor moderada, o IAF e o uso do solo}

\section{ilha de calor moderado}

\begin{tabular}{l|l|l|l}
\hline eixos & uso do solo & IAF & distritos \\
\hline $\mathbf{8 e 9}$ & $\begin{array}{l}\text { residencial horizon- } \\
\text { tal de médio e alto } \\
\text { padrão }\end{array}$ & $0,0-0,038$ & $\begin{array}{l}\text { Ponte Rasa, Penha, Cangaiba, Ermelino Ma- } \\
\text { tarazzo, Fraguesia do Ó, Limão, Casa Verde e } \\
\text { Pirituba }\end{array}$ \\
\hline $\mathbf{9}$ & $\begin{array}{l}\text { residencial horizontal } \\
\text { de baixo padrão }\end{array}$ & $0,0-0,51$ & $\begin{array}{l}\text { Itaim Paulista, Itaquera, Lajedo, Vila João, } \\
\text { Jardim Helena, Cidade Dutra, Rio Pequeno e } \\
\text { Raposo Tavares }\end{array}$ \\
\hline
\end{tabular}


A ilha de frescor urbana apresentou elevada concentração de vegetação. Os padrões de uso do solo mais representativos para essa categoria foram o residencial vertical de alto/médio padrão e o residencial/comércio e serviços. Nas áreas residenciais, os valores do IAF variaram entre 0,01 e 0,66 e, nos ambientes vegetados, ficou entre 0,39 e 0,83 (Tabela 4).

\section{Tabela 4 - Tabulação da correlação entre a ilha de frescor urbana, o IAF e o uso do solo}

\section{ilha de frescor urbana}

\begin{tabular}{l|l|l|l}
\hline eixos & uso do solo & IAF & distritos \\
\hline 10 & $\begin{array}{l}\text { residencial vertical de } \\
\text { médio e alto padrão }\end{array}$ & $0,0-0,066$ & $\begin{array}{l}\text { Vila Andrade, Itaim Bibi, Moema, Saúde, Vila } \\
\text { Mariana, Liberdade, Perdizes, Tatuapé, Consola- } \\
\text { ção e Santana }\end{array}$ \\
\hline 10 & $\begin{array}{l}\text { residencial } \\
\text { comércio e serviços }\end{array}$ & $0,0-0,38$ & $\begin{array}{l}\text { Pinheiros, Liberdade, Pirituba, Jardim Paulista e } \\
\text { Itaim Bibi }\end{array}$ \\
\hline
\end{tabular}

\section{Considerações finais}

A presença baixa ou a total ausência de vegetação apresentou-se como a principal causa da distribuição espacial e da intensidade da ilha de calor urbana. Quanto ao uso do solo, a variável que estabeleceu melhor relação espacial com o fenômeno foi o de armazéns/indústria, comércio e serviços, ou seja, a abundância de asfalto, concreto e telhados de zinco, amianto e alumínio desses ambientes ensejam maior propagação e armazenamento de calor, o que aumenta a diferença de temperatura da superfície em mais de $8^{\circ} \mathrm{C}$ com relação aos ambientes rurais.

Os quadros descritos no estudo apontam a importância de se preservarem áreas de parque e unidades de conservação, que concorrem significativamente para amenizar as temperaturas da superfície. Além disso, é muito necessário expandir o arboreto urbano e as áreas verdes em geral, pois, mesmo quando em meio a condensadas áreas urbanas, os distritos com altos índices de biomassa vegetal apresentam características de ilhas de frescor.

A principal limitação metodológica deste estudo é a pequena variedade dos tipos de cobertura analisados: apenas áreas com diferentes valores de biomassa vegetal ou sem ela. Assim, não se contemplaram outros dados de cobertura como porcentagem de concreto, asfalto e os tipos dos telhado. Essa restrição se deve à inexistência dos dados na escala dos mapeamentos adotados aqui, e não se completou a análise comparativa entre os tipos de cobertura do solo e a temperatura da superfície, o que dificultou o estabelecimento de relações lineares dentro da análise espacial.

$\bigcirc$ presente estudo partiu da análise simples da relação espacial entre a combinação da cobertura vegetal, do uso do solo e de suas respectivas respostas térmicas nos distritos municipais. Alguns fatores relevantes para entender a conformação espacial do fenômeno - como a circulação atmosférica da camada limite urbana diante das condições geomorfológicas do sítio e da morfologia urbana - não foram levados em conta, pois a escala de 1:246.000 não privilegia esse tipo de análise. 
Diante da realidade medida e analisada neste trabalho, propomos o desenvolvimento de estudos interdisciplinares que procurem entender a relação entre a ilha de calor urbana e outros fenômenos como a concentração de poluentes e gases atmosféricos, sua precipitação e seu escoamento, alteração das amplitudes térmicas em escala de detalhe e suas possíveis consequências na morbidade e mortalidade por doenças do aparelho circulatório.

\section{Referências}

ALLEN, R. G., TREZZA, R.; TASUMI, M. Surface energy balance algorithms for land. Advance training and users manual, version 1.0, 2002.

CATUZZO, H. Telhado verde: impacto positivo na temperatura e umidade do ar. $\bigcirc$ caso da cidade de São Paulo. Tese (Doutorado em Geografia Física) - Faculdade de Filosofia, Letras e Ciências Humanas, Universidade de São Paulo, São Paulo, 2013.

FERREIRA, M. J.; OLIVEIRA, A. P.; SOARES, J. Anthropogenic heat in the city of São Paulo, Brazil. Theoretical and Applied Climatology, v. 101, p. 9-19, 2010.

FERREIRA, M. J. et al. Radiation balance at the surface in the city of São Paulo, Brazil: diurnal and seasonal variations. Theoretical and Applied Climatology, v. 107, p. 229-246, 2012.

FERREIRA, M. J.; OLIVEIRA, A. P.; SOARES, J. Diurnal variation in stored energy flux in São Paulo city, Brazil. Urban Climate, v. 5. p. 36-51, 2013.

HUETE, A. R. Adjusting vegetation indices for soil influences. International Agrophysics, v. 4, n. 4, p. 367-376, 1988.

IBGE (2010)

IBGE. INSTITUTO BRASILEIRO DE GEOGRAFIA E ESTATÍSTICA. Disponível em: $<$ http://cidades.ibge.gov.br/xtras/perfil.php?lang $=\varepsilon$ codmun $=355030$ Esearch $=\mid$ | info gr\%Elficos:-informa\%E7\%F5es-completas>. Acesso em: 15 abr. 2014

LAAIDI, K. et al. The Impact of Heat Islands on Mortality in Paris during the August 2003 Heat Wave. Environmental Health Perspectives, v. 120, n. 2, p. 254-259, 2012.

LOMBARDO, M. A. Itha de calor nas metrópoles: o exemplo de São Paulo. São Paulo: Hucitec/Lalekla, 1985.

MATSON, M. et al. Satellite Detection of Heat Islands. Monthly Weather Review, v. 106, n. 2, p. 1725-1734, 1978.

McMICHAEL, A. J. et al. International study of temperature, heat and urban mortality: the 'ISOTHURM' project. International Journal of Epidemiology, v. 37, n. 5, p. 1121-1131, 2008.

OKE, T. R. Boundary Layer Climates. London: Methuen, 1978.

OKE, T. R. et al. The energy balance of central Mexico City during the dry season. Atmospheric Environment, v. 33, n. 24/25, p. 3919-3930,1999.

$\operatorname{PMSP}(2000)$ 
PMSP. PREFEITURA DO MUNICÍPIO DE SÃO PAULO. Atlas Ambiental. Disponível em $<w w w . a t l a s a m b i e n t a l . s p . g o v . b r>$. Acesso em: 1 abr. 2015.

RIBEIRO, H. P. Ilha de calor na cidade de São Paulo: sua dinâmica e efeitos na saúde da população. Tese (Livre-docência em Gerenciamento Ambiental) - Faculdade de Saúde Pública, Universidade de São Paulo, São Paulo, 1996.

SILVA, B. B.; LOPES, G. M.; AZEVEDO, P. V. Balanço de radiação em áreas irrigadas utilizando imagens Landsat 5-TM. Revista Brasileira de Meteorologia, v. 20, n. 2, p. $243-$ 252, 2005.

TARIFA, J. R.; ARMANI, G. Unidades climáticas urbanas. In: TARIFA, J. R.; AZEVEDO, T. R. (Org.). Os climas da cidade de São Paulo: teoria e prática. São Paulo: Pró-reitoria de Cultura e Extensão/Laboratório de Climatologia/FFLCH, 2001. p. 47-70. (Coleção Novos Caminhos, 4.) 